\title{
O que revelam os mapas mentais do quinto ano? Um estudo de caso com estudantes do ensino fundamental
}

\author{
What do fifth-year mind maps reveal? \\ A case study with elementary school students
}

\section{¿Qué revelan los mapas mentales de quinto año? Un estudio de caso con estudiantes de escuela primaria}

\author{
Aline Beatriz Ludwig \\ https:/ / orcid.org/0000-0002-5603-5961 \\ ludwig.aline@gmail.com \\ Instituto Federal de Santa Catarina, IFSC, São Carlos, SC \\ Rosa Elisabete Militz Wypyczynski Martins \\ https:/ / orcid.org/0000-0002-2875-2883 \\ rosa.martins@udesc.br \\ Universidade Estadual de Santa Catarina, UDESC, Florianópolis, SC
}

\begin{abstract}
Resumo: Este artigo apresenta reflexões acerca do ensino da geografia escolar, tendo como foco a aprendizagem dos conhecimentos cartográficos. O objetivo principal foi verificar o entendimento de noções cartográficas de estudantes de quinto ano do ensino fundamental, por meio da linguagem cartográfica presente em representações criadas por eles. A análise foi baseada na metodologia proposta por Kozel (2001) ao examinar os mapas mentais nas representações gráficas, como a forma de representação, a distribuição e a especificidade dos elementos e, por fim, a proporção observada entre os elementos reais e representados. Ao observar estes elementos nas representações, constata-se a importância de trabalhar, nos anos iniciais, com atividades que desenvolvam os conhecimentos cartográficos no âmbito do processo de ensino-aprendizagem da Geografia.
\end{abstract}

Palavras-chave: Cartografia escolar, Geografia escolar, Ensino-aprendizagem.

Abstract: This paper presents reflections about the teaching of school geography, focusing on the learning of cartographic knowledge. The main goal was to verify the understanding of cartographic views of fifth-year elementary school students, through the cartographic language present in representations of selected students. The analysis was based on Kozel (2001) to examine mental maps concerning to its graphic representations, such as the form of representation, distribution and specificity of the elements and, finally, the proportion observed between the real and represented elements. By observing these elements in the representations, it is observed the importance of working, in the initial years, with activities that develop the cartographic knowledge within the teaching-learning process of Geography.

Keywords: School cartography, School geography, Teaching-learning. 
Resumen: Este artículo presenta reflexiones sobre la enseñanza de la geografía escolar, centrándose en el aprendizaje del conocimiento cartográfico. El objetivo principal era verificar la comprensión de las opiniones cartográficas de los estudiantes de la escuela primaria de quinto año, a través del lenguaje cartográfico presente en las representaciones creadas por ellos. El análisis se basó en la metodología propuesta por Kozel (2001), que tiene como parámetro examinar los mapas mentales con respecto a las representaciones gráficas, como la forma de representación, distribución y especificidad de los elementos y, por último, la proporción observada entre los elementos reales y representados. Al observar estos elementos en las representaciones, se observa la importancia de trabajar, en los primeros años, con actividades que desarrollen el conocimiento cartográfico dentro del proceso de enseñanza-aprendizaje de la Geografía.

Palabras clave: Cartografía escolar, Geografía escolar, Enseñanza-aprendizaje.

\section{INTRODUÇÃO}

Este estudo retoma um dos temas analisados originalmente na dissertação de mestrado de Ludwig (2017), com foco principal na aprendizagem dos conhecimentos cartográficos nos anos iniciais do ensino fundamental. Interessa, particularmente, compreender qual o entendimento dos estudantes do quinto ano dos anos iniciais do ensino fundamental em relação aos conhecimentos cartográficos.

Segundo pesquisadores sobre o ensino-aprendizagem de Geografia nos anos iniciais - como Rosa (2008), Zuba (2006) e Braga (2006) - frequentemente constata-se que os conteúdos de Cartografia são de difícil aprendizagem pelos estudantes. Da mesma forma, a literatura relacionada a esta questão aponta muitos obstáculos a serem superados no que se refere aos conhecimentos cartográficos no âmbito do ensino de Geografia.

Acreditamos que estas dificuldades na aprendizagem nos temas correlatos à Cartografia podem estar relacionadas ao processo de Alfabetização Cartográfica que deve acontecer nos anos iniciais. Nesta fase da escolarização, segundo Oliveira (2010), devem ser trabalhadas as noções básicas de cartografia, e a percepção do espaço de vivência da criança deve ocorrer juntamente com a alfabetização da escrita e da leitura, pois neste momento os estudantes desenvolvem suas primeiras percepções sobre o mundo. Trabalhada de forma efetiva nos primeiros anos da escolarização, a Alfabetização Cartográfica possibilita ao estudante, nos anos posteriores, desenvolver capacidades cognitivas mais complexas sobre as aplicações e possibilidades de entendimento do espaço.

As aproximações com a Cartografia contribuem para o entendimento dos estudante acerca do seu cotidiano e na relação deste com os conteúdos trabalhados em sala de aula, além de possibilitar a experiência de representação do espaço. Na cartografia escolar, as representações tornam-se fundamentais para o entendimento da evolução de um pensamento crítico acerca do espaço.

Em tal contexto, surgiu a ideia do trabalho com os mapas mentais, numa tentativa de aproximar a linguagem cartográfica das crianças por meio de uma abordagem menos 
cartesiana. Dentro do rigor que baliza o conhecimento cartográfico formal, os mapas utilizam escala, sistema de projeção e coordenadas; já os mapas mentais expressam a percepção de um espaço por meio de símbolos e a afetividade de quem o produziu.

Neste sentido, pode-se afirmar que o domínio da linguagem cartográfica se revelou uma necessidade fundamental para os professores que ministram aulas nos anos iniciais com o ensino de Geografia. Tem-se verificado que, em algumas escolas, as práticas que envolvem noções da Cartografia na disciplina de Geografia muitas vezes não são significativas para os estudantes, devido às dificuldades de abordagem por parte dos professores ao trabalhar com os conhecimentos cartográficos. Assim, o objetivo geral desta pesquisa foi o de analisar, por meio dos mapas mentais, o nível de desenvolvimento das relações espaciais dos estudantes do quinto ano do ensino fundamental, avaliando como eles usam os conhecimentos cartográficos na prática.

\section{REFLEXÕES SOBRE A CARTOGRAFIA NA GEOGRAFIA ESCOLAR DO ENSINO FUNDAMENTAL}

Seja na escola ou fora dela, a Geografia está cotidianamente presente em nossas vidas. Com alguma frequência observa-se que esse fato passa despercebido na vida das pessoas, por essa razão costumeiramente também não se vê importância em aprender Geografia.

Muito antes de chegar à escola, a criança já interage com o mundo, reconhece alguns lugares, porém ainda não o compreende na sua totalidade. Isso se deve ao fato de que a criança caminha, corre, brinca, no e com o espaço, e aos poucos vai reconhecendo sua complexidade. Neste sentido, na escola, a Geografia tem o papel de fazer com que o estudante se reconheça no espaço, na sua própria constituição e na sociedade em que faz parte.

A Geografia escolar possibilita decodificar a realidade sob o olhar espacial, na medida em que o aluno contrapõe o conhecimento que traz consigo aos conceitos cientificamente elaborados, produzindo então o seu próprio conhecimento (Callai, 2003). Neste sentido, ensinar as crianças dos anos iniciais apenas a ler palavras e decodificar símbolos não garante integralmente sua formação cidadã. É preciso, também, promover a leitura do mundo, a leitura do espaço social, que é físico, cultural, econômico, etc., construído e desconstruído pelo homem e pela natureza. As contribuições da Geografia nos anos iniciais, em que a criança passa pelo processo de alfabetização, longe de ter um papel secundário, deve ser um componente significativo na busca da leitura e do escrever, as palavras e o mundo. Callai destaca que, ao "ler o espaço, a criança estará lendo a sua própria história, representada concretamente pelo que resulta das forças sociais e, particularmente, pela vivência de seus antepassados e dos grupos com os quais convive atualmente" (Callai, 2005, p. 237).

Callai reafirma a importância de desenvolver, no momento da alfabetização, a capacidade de ler não só palavras, mas também o espaço e aparências das paisagens para desenvolver a capacidade de entender os significados que elas expressam. A autora refere-se à leitura do espaço geográfico por meio da linguagem geográfica, constituída a partir de um corpo conceitual da Geografia e permeada por conceitos que são requisitos para a análise dos fenômenos do ponto de vista geográfico (Cavalcanti, 2004). Quando nos 
referimos a ler e escrever o mundo, estamos relacionando o ler o espaço à necessidade do aluno em dominar procedimentos como observar, descrever, e interpretar conceitos básicos como a paisagem, o lugar, e o território. Escrever o espaço geográfico significa desenhar e representar através de símbolos os elementos percebidos no espaço.

Portanto, pensar sobre o espaço geográfico é também pensar sobre sua representação, conhecer a cidade, o bairro, dinâmicas populacionais, etc. Implica em dominar as formas de representá-los. A apropriação da linguagem cartográfica é um aspecto determinante para leitura e compreensão das representações presentes nos diferentes mapas.

Entendemos, portanto, a linguagem cartográfica como um conhecimento essencial para o entendimento de conceitos geográficos pelas crianças, pois se tratando de uma linguagem que tem como um dos seus objetivos representar a realidade, facilita a apreensão desses conceitos no início da escolarização. A representação vai muito além do ato de elaborar um mapa ou diagrama, de não separar a construção teórica de sua representação, mas entender quando se torna mais adequado o uso ou não de uma determinada representação e em qual linguagem ela se torna mais efetiva.

Neste sentido, Francischett (2007) destaca a importância da linguagem cartográfica no ensino de Geografia, e afirma que sua contribuição vai muito além à compreensão dos mapas. Esta linguagem contribui para desenvolver nos estudantes capacidades cognitivas relativas à representação do espaço e do espaço na representação e, ainda, oferecendo a compreensão necessária para que se construam conhecimentos fundamentais de leiturização na Geografia. No entanto, Katuta (2015), chama a atenção para alguns pressupostos para a apropriação e uso da linguagem cartográfica, entendido o contexto da construção de conhecimentos geográficos, o que significa dizer que não se pode usá-la por si só, mas como dispositivo primordial para elaboração de saberes sobre território, regiões, lugares e outros.

Se a supervalorizarmos, em detrimento do saber geográfico, corremos o sério risco de defender a linguagem por ela mesma, o que esvazia em importância e significado tanto no ensino superior quanto básico. É preciso que ocorra a aprendizagem e o uso da linguagem cartográfica para, sobretudo entendermos a lógica da reprodução dos territórios; caso contrário, ela perde seu sentido ou razão de ser no ensino geográfico (Katuta, 2015, p. 133).

A autora afirma, ainda, que os conhecimentos cartográficos devem iniciar com o estudo do espaço concreto do aluno, o mais próximo dele, como a sala de aula, a escola, bairro e assim, gradativamente, até atingir espaços maiores como o município, estado e país. É preciso conceber a alfabetização de forma mais ampla. Esse processo não deve ser entendido como mera decodificação das convenções e do alfabeto cartográfico, pois o objetivo não é ensinar a cartografia, mas ensinar por meio dela (Katuta, 2015).

Desta forma, entendemos que a aprendizagem dos conhecimentos cartográficos e a aquisição da linguagem cartográfica representam muito mais do que fatores de potencialização do ensino da Geografia e da compreensão de mapas. A aprendizagem destes conceitos contribui para o desenvolvimento cognitivo da criança de modo geral, e, 
consequentemente, para o processo de alfabetização como um todo, mobilizando saberes de múltiplas áreas do conhecimento.

\section{OS MAPAS NA GEOGRAFIA ESCOLAR E OS MAPAS MENTAIS}

A Cartografia possibilita diferentes formas de representar o espaço geográfico, como mapas, globo terrestre, croquis, maquetes, entre outras, que, quando exploradas de forma coerente aos conhecimentos geográficos, possibilitam um raciocínio espacial. No entanto, os mapas possuem uma expressividade maior, pois além de serem usados em diferentes áreas do conhecimento, fazem-se presentes em variados usos do cotidiano, sendo comuns em noticiários, em mídias impressas e digitais, e outros meios de divulgação. Assim, ao falar sobre Geografia e Cartografia, quase que de forma involuntária surgem em nossas mentes os mapas. Esta relação é inevitável, pois este instrumento representativo possui alto poder de espacialização e sintetização das informações.

Embora seja bastante viabilizada pelo domínio da dimensão técnica, a concepção de mapas vai muito além disso, pois mapas expressam ideias e visões sobre o mundo. Como bem afirma Harley (2009, p. 2):

Os mapas nunca são imagens isentas de juízo de valor e, salvo no sentido euclidiano mais estrito, eles não são por eles mesmos nem verdadeiros nem falsos. Pela seletividade de seu conteúdo e por seus símbolos e estilos de representação, os mapas são um meio de imaginar, articular e estruturar o mundo dos homens.

Contudo, mesmo considerada uma linguagem fundamental no ambiente escolar, por muitas vezes, ainda, é subutilizada e/ou empregada de forma equivocada, como um conteúdo técnico específico da Geografia ou apenas como mera ilustração. Este fato também é evidenciado nos primeiros anos de escolaridade, quando deveria acontecer a Alfabetização Cartográfica. Conforme destacado nos estudos em investigações de Simielli (2013), Castrogiovanni (2014) e Callai (2014), as crianças chegam ao quinto ano do ensino fundamental sem a construção das noções e das elaborações conceituais que compreenderiam tal alfabetização. Tais autores destacam, ainda, que este problema tem sido comum e é importante que, mesmo nos anos mais avançados da escolarização, sejam elaboradas atividades visando promover o aprendizado destas noções.

Se levarmos em consideração critérios rigorosos da ciência cartográfica, muitas das representações espaciais não serão consideradas como mapas. Uma definição de mapa, ponderando os rigores técnicos desta ciência, é descrita por Oliveira (1993, p. 322):

Representação gráfica, geralmente numa superfície plana e em determinada escala, das características naturais e artificiais, terrestres ou subterrâneas, ou, ainda, de outro planeta. Os acidentes são representados dentro da mais rigorosa localização possível, relacionados, em geral, a um sistema de referência de coordenadas. Igualmente, uma representação gráfica de uma parte ou do total da esfera celeste. 
No entanto, nos referimos a um conceito mais amplo de mapa, com uma maior preocupação com o usuário. Souza e Katuta (2001) aprofundam essa reflexão, baseados no conceito proposto por Joly (1990):

[...] se uma representação de toda ou parte da superfície terrestre, for uma imagem simplificada do real, tiver uma determinada convenção e guardar uma certa proporcionalidade com o objeto representado (escala), podemos considerar esse mesmo material como um mapa (Souza \& Katuta, 2001, p. 110).

Mesmo que neste trabalho, o objetivo não seja discorrer sobre a aprendizagem do mapa em seu plano cartesiano, com normas técnicas e padrões formais, por outro lado ressaltamos também a importância destes nas atividades escolares, visto sua forte expressão e necessidade na vida contemporânea.

Cabe salientar a importância da linguagem cartográfica, aqui entendida como um sistema de signos, formada e interpretada a partir de relações espaciais que contêm os significados da representação gráfica. Seja no meio escolar ou na sociedade, esta deve ser entendida como uma linguagem de comunicação por excelência para exprimir ideias e sentimentos sobre o mundo direta ou indiretamente experimentado. Seemann (2003) corrobora e destaca, que as representações do espaço estão ameaçadas de perder seu significado numa sociedade sobrecarregada de imagens.

Por isso, cabe ao professor estar atento à dimensão abstrata que carregam, adequando-a aos estudantes a fim de potencializar o aprendizado. Assim, pode-se lançar mão de procedimentos e atividades não formais ou 'alternativos' de ensino, renunciando por um momento às normas técnicas da Cartografia, para ressaltar os conhecimentos que os estudantes já possuem dos espaços que vivem e do modo como os representam (Nascimento \& Ludwig, 2015).

Compreender o mapa em um conceito mais amplo abre uma gama de possibilidades para entender como os mapas foram confeccionados e quais as intenções que apresentam. Logo, um mapa ao ser criado, independente das representações que ele venha a conter, tem uma intencionalidade diretamente relacionada aos caminhos culturais em que o autor está imerso, e que não devem ser desconsiderados em momento algum.

Com base nesses pressupostos o mapa mental se apresenta como um instrumento importante na contribuição ao ensino de Geografia, com o objetivo de ampliar as perspectivas espaciais dos estudantes para além da leitura dos textos ou dos mapas convencionais. Não podemos aceitar que o mapa seja visto somente como um objeto distante da produção do estudante, por este não dominar todas as normas e os padrões que estabelecem corretamente a configuração de uma representação cartográfica. Entendemos que a proposta do uso dos mapas mentais é muito significativa pois esse tipo de representação apresenta ao estudante uma maneira diferente de analisar o espaço e, principalmente, desmistifica a concepção de que o mapa é uma leitura singular, fixa e padronizada da realidade.

Diferente das representações cartográficas formais, as representações provenientes das imagens mentais não existem dissociadas do processo de leitura que se faz do mundo. E nesse contexto, os mapas mentais são considerados como uma representação do mundo 
real visto através do olhar particular de um ser humano, passando por seu aporte cognitivo, sua visão de mundo e intencionalidades (Kozel, 2010). Os mapas mentais possibilitam ainda ao seu autor, incluir elementos subjetivos que, na maioria das vezes, não estão presentes nos mapas tradicionais (Richter, Marin \& Decaninni, 2010). Os mapas mentais não se originam necessariamente na vivência em espaços concretos, podendo ser formados na mente humana a partir de um diálogo, da leitura de um livro, ou mesmo através da mídia.

Como atividade no ensino da Geografia, esta proposta vem sendo estudada e discutida por vários pesquisadores, como Kozel (2013, 2010, 2008), Richter (2011), Simielli (2013), e Pontuschka, Paganelli e Cacete (2009). Para Simielli (2013), é possível observar, por meio do mapa mental, se o aluno tem uma percepção efetiva da ocorrência de um fenômeno no espaço e condições de fazer a sua transposição no papel. A construção destas representações possibilita a valorização da autonomia na elaboração de suas próprias representações a partir dos conhecimentos prévios dos estudantes, ligando-os ao conhecimento científico.

Enquanto resultantes da subjetividade das pessoas, os mapas mentais estão impregnados de juízo de valor, pois sendo produtos sociais, carregam elementos históricos e culturais de quem os produziu. A elaboração dos mapas mentais possibilita maior desenvolvimento da capacidade e liberdade criativa, podendo cada estudante expressar, a partir das suas lentes, como vê o mundo a sua volta por meio da uma linguagem não verbal. Esta atividade ainda permite ao estudante demonstrar o que realmente conhece do espaço em que está inserido, pois o convívio com os signos faz com que ele perceba ativamente o que está em sua volta, não podendo buscar na mente algo que foi decorado para uma determinada atividade de avaliação.

\section{O QUE REVELAM OS MAPAS MENTAIS ANALISADOS}

Os sujeitos desta pesquisa, realizada no ano de 2016, foram estudantes de duas turmas de quinto ano do Ensino Fundamental de escolas estaduais do município de Florianópolis, SC. Partimos do pressuposto que neste período escolar os estudantes já tenham passado pelo processo de iniciação da aprendizagem cartográfica, pois a partir do sexto ano, com professores específicos de cada área, os conhecimentos cartográficos passam a ser tratado de forma mais direta e aprofundada, exigindo alguns conhecimentos e noções preliminares para seu entendimento. No entanto, Simielli (2013), Castrogiovanni (2014) e Callai (2014) tem ressaltado dificuldades de estudantes de sextos anos em relação aos conhecimentos cartográficos básicos.

Dos 43 estudantes que participaram da pesquisa, a maioria (34) situava-se na faixa etária de 10 e 11 anos (quatro estudantes possuíam 12 anos, outros quatro 13 anos, e apenas um com 15 anos). Não foi feita a distinção por sexo, nem por nível socioeconômico, pois nossa preocupação central foi verificar o entendimento dos conhecimentos cartográficos apreendidos ao longo do período escolar frequentado até o momento da pesquisa.

Para a realização da atividade, foi disponibilizado uma folha de papel A4 contendo espaço para identificação (nome fictício para preservar a identidade dos sujeitos), registro da idade dos estudantes, e um retângulo demarcado para o desenho dos mapas. Os 
estudantes tiveram a liberdade de usar qualquer tipo de material (lápis, caneta, lápis de cor, entre outros), assim como orientar a folha no formato retrato ou paisagem, conforme sua preferência. Com duração de duas horas-aula (90 minutos), a maioria dos estudantes concluiu a atividade antes do prazo (poucos tiveram dificuldades em terminar dentro do tempo determinado).

Todos os estudantes receberam a mesma orientação, a de representar o seu caminho de casa até a escola, incluindo o máximo de informações que considerassem relevantes. A escolha deste percurso (casa-escola), é significativa pelo fato de a criança vivenciar este espaço todos os dias e ser um parâmetro comum a todas, ou seja, todos os estudantes realizam um trajeto diariamente para chegar à escola, independente do meio utilizado. É importante salientar que não foram ministradas (por parte da pesquisadora que realizou a atividade) aulas nem exposições relacionadas à Cartografia, a fim de não direcionar e nem intervir na elaboração das representações cartográficas.

A base de nossa análise foi elaborada a partir da metodologia proposta por Kozel (2001), que tem como parâmetro analisar mapas mentais no que tange às representações gráficas, com algumas adequações a nossa pesquisa. A mesma foi organizada em quatro etapas:

\section{I - Interpretação quanto à forma de representação dos elementos da imagem}

Nesta categoria, podem-se classificar os elementos da imagem considerando os seguintes aspectos:

- Ícones: formas de representação gráficas através de desenhos;

- Letras: palavras complementando as representações gráficas;

- Mapas: forma de representação cartográfica que evidencia a espacialização do fenômeno representado.

II - Interpretação quanto à distribuição dos elementos na imagem

Devem-se observar os seguintes aspectos:

- Representação da imagem em perspectiva;

- Representação da imagem em forma horizontal;

- Representação da imagem em vertical.

III - Interpretação quanto à especificação dos ícones

Requer uma análise mais detalhada. Foram selecionados os seguintes grupos de classificação:

- Representando elementos da paisagem natural, como vegetação, nuvens, rios, etc.;

- Representando elementos da paisagem construída, onde há presença de casas, prédios, indústrias, etc.;

- Representação de elementos humanos - presença de pessoas ou grupos de pessoas; - Representação dos elementos móveis, equivalente aos meios de transporte, onde a mobilidade de um lugar para outro dá a sensação de movimento no lugar (carro, ônibus, trem, etc.). 
IV - Apresentação de outros aspectos ou particularidades

Neste quesito a metodologia desenvolvida por Kozel deixa em aberto as possíveis particularidades ou mensagens veiculadas pelos mapas mentais como textos a serem desvendados. Nesta pesquisa, direcionamos este item para a análise dos aspectos relacionados à cartografia não contemplados nos outros itens, como por exemplo a noção de proporção. A noção de proporção está atrelada ao uso da escala adequada para representar os elementos. A análise se baseia em como os elementos da imagem estão representados em comparação com o tamanho real e com os elementos vizinhos.

As noções espaciais básicas para o entendimento da cartografia possibilitam a criança fazer a construção e representação gráfica, à medida que produz ação sobre o espaço. Nesse sentido, é importante frisar que, para estabelecer um conhecimento mais aprofundado das noções espaciais, é necessário que se desenvolvam atividades práticas passo a passo com crianças, desde o início de sua escolarização.

\section{RESULTADOS E DISCUSSÃO}

Ao analisar os mapas mentais, é preciso procurar seu sentido, focando na intenção do que foi representado (Kozel, 2007). Ou como acrescenta Tuan, que ao contemplar uma obra de arte: "é importante o conhecimento da história crítica, porque mantém presa a atenção na obra, enquanto os sentidos se recuperam" (Tuan, 1980, p. 108). Assim, procedemos a leitura dos mapas mentais como se o entrevistado fosse um artista que imagina sua vida e relembra fatos que podem ser registrados naquele desenho. O desenho traz em seu conteúdo a expressão do pensar e do sentir do indivíduo. Alia-se a isso o interesse científico e as reflexões teóricas, para se chegar a uma análise final.

No primeiro mapa (Fig. 1), uma estudante de 11 anos representa a paisagem construída: sua casa, os principais estabelecimentos comerciais - como supermercado (Angeloni) e shopping (Iguatemi), uma instituição financeira (Caixa Econômica), um posto de combustíveis e, por fim, a escola. O caminho é representado apenas por uma linha interligando os demais elementos, seguindo uma sequência. De acordo com a primeira categoria, a representação dos elementos é baseada em ícones, ou seja, representação gráfica em forma de desenho, complementada por letras. Observa-se a presença de elementos humanos e móveis, no entanto não há presença de elementos naturais. É possível observar também elementos de orientação, como a rosa dos ventos e outra indicação a oeste, sobre a escola. Ambas orientam para direções diferentes, demonstrando o uso não adequado destes elementos. 
Figura 1: Mapa mental - Thaynarah, 11 anos.

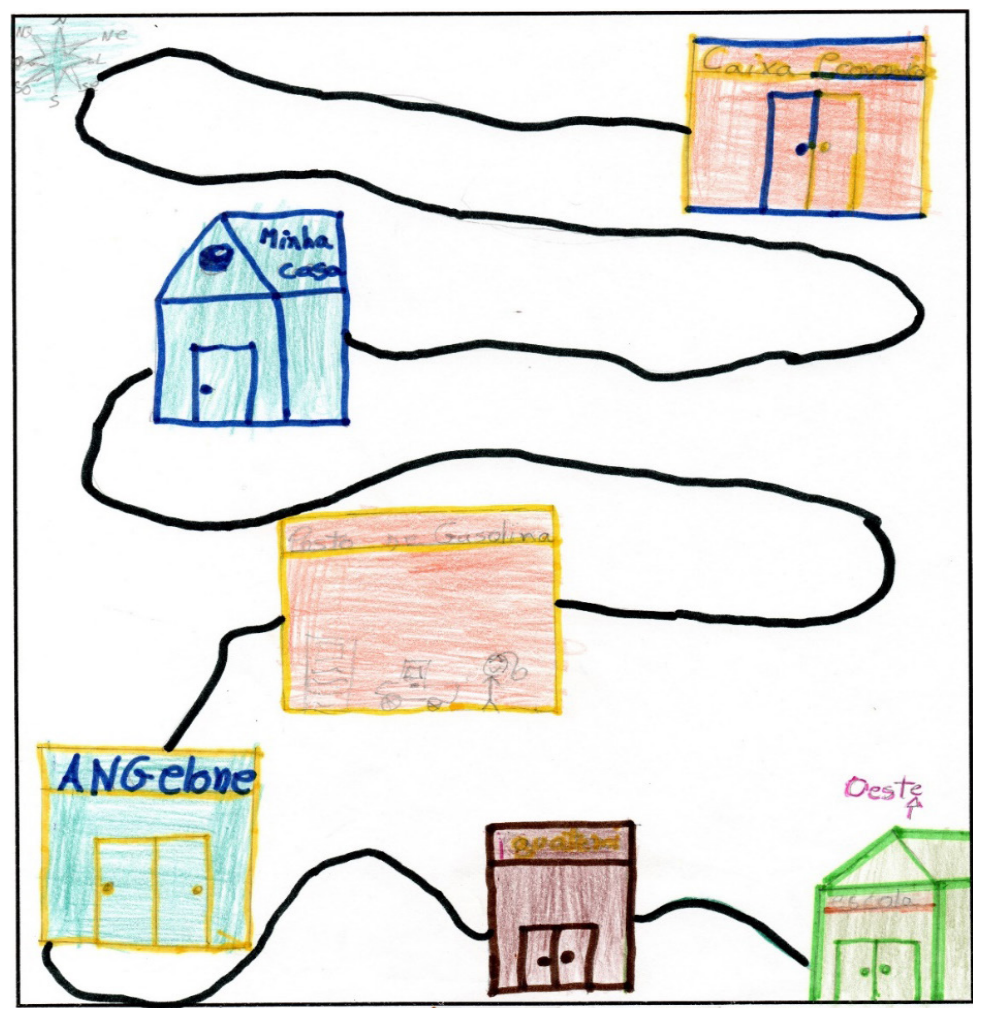

Constata-se o desenvolvimento das relações espaciais topológicas elementares, observadas a partir da organização dos objetos próximos e contíguos correspondendo a relação de vizinhança, assim como a disposição ordenada do seu caminho. Almeida e Passini (2015, p. 32) reforçam este argumento esclarecendo que "os objetos ocupam uma posição anterior, intermediária ou posterior a partir de um determinado ponto de vista, sendo que a percepção de cada elemento e sua relação com os demais leva à relação de envolvimento". As autoras exemplificam este processo usando a lógica das paradas de um metrô, que é passível de comparação com a ilustração acima.

Observa-se também a imaturidade espacial com aparecimento de fenômenos como a transparência, que ocorre no elemento 'Posto de Gasolina'. De acordo com Piaget (1978), este fenômeno é característico da fase de esquematismo, desenvolvida de 7 a 10 anos, que faz parte da fase das operações concretas e revela a dificuldade de esboçar elementos tridimensionais em bidimensionais.

O mapa mental representado por Felicyte (Fig.2) também baseou sua representação na paisagem construída, destacando alguns estabelecimentos comerciais ao longo do caminho (dois supermercados e salão de beleza), incluindo sua casa e a escola como pontos de partida e chegada, respectivamente. Seu mapa mental também é baseado em ícones, representação gráfica em forma de desenho, e letras complementando a representação. 
Figura 2: Mapa mental - Felicyte, 10 anos.

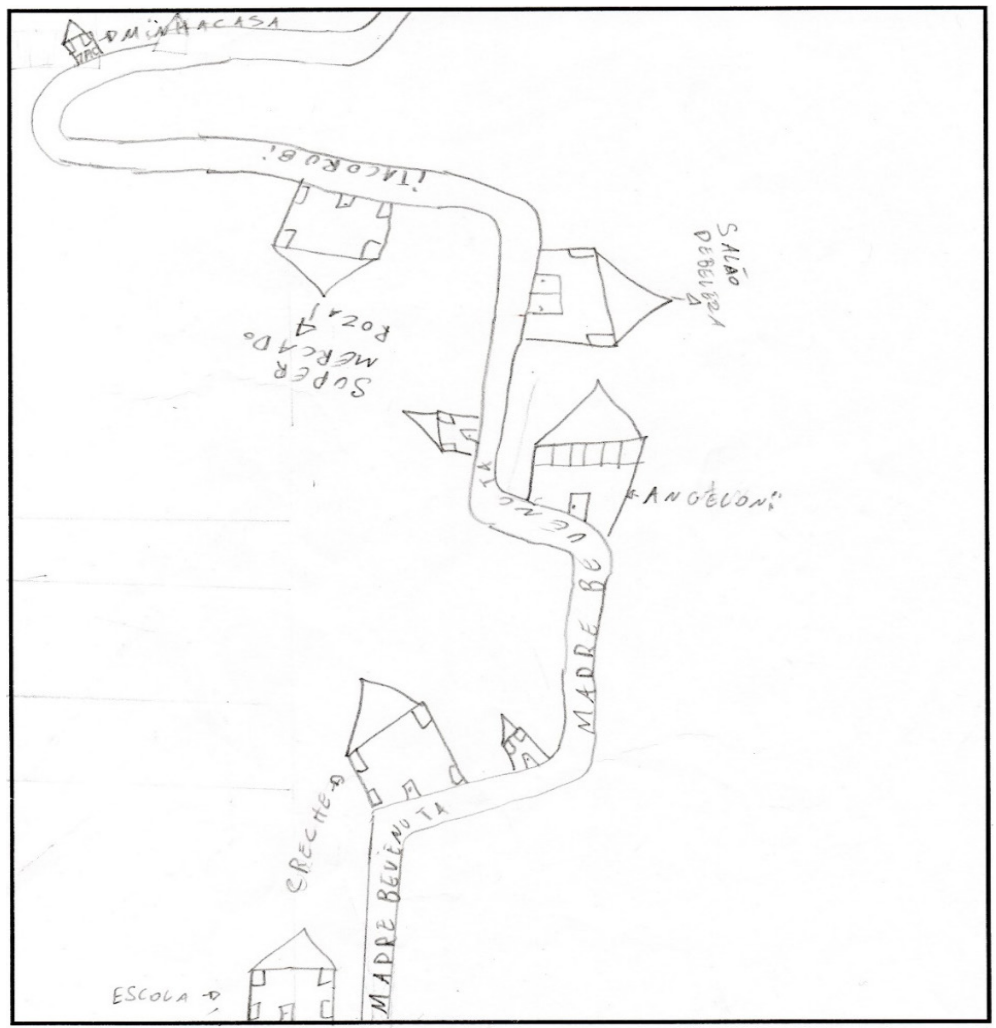

Neste segundo mapa, observa-se que a estudante indica por meio de letras os ícones, assim como também a via de acesso e o nome do bairro, indicando um conhecimento sobre o espaço em que circula, o que sugere uma percepção mais desenvolvida do seu caminho até a escola. As palavras presentes nas representações demonstram o que o estudante deseja indicar o que corresponde a determinado lugar. A presença das letras evidencia o que o aluno quer destacar em seu mapa mental. Isso aumenta a ideia de representação e início de legenda.

No mapa da Figura 2 é possível observar uma maturidade espacial maior do que a apresentada no mapa da Figura 1, porém, a mistura dos pontos de vista ainda é marcante; apenas a rua foi representada de forma vertical (vista de cima), o restante dos elementos construídos aparecem a partir do ponto de vista horizontal tendo como linha de base a própria rua. A descontinuidade na representação demonstra a necessidade de construção de algumas noções de observação, uma vez que a área é densamente ocupada. De acordo com Almeida (2014, p. 30), "apesar de as crianças conceberem pontos de vistas diferentes, estão longe de saber coordená-los dentro de um único sistema de perspectiva". Sendo comum a mistura de pontos de vista em um mesmo desenho durante o processo de desenvolvimento de perspectiva.

No mapa mental a seguir (Fig. 3), pode-se observar elementos da paisagem construída, como casas e prédios, elementos móveis, como carros, e elementos da paisagem natural, como o sol e árvores. Os elementos representados apresentam-se em diferentes pontos de vista: os elementos naturais, prédios e casas estão representados a partir de um ponto de vista horizontal; já o caminho e os elementos móveis aparecem na vertical. 
Nesse exemplo, parece ficar claro que a criança já concebeu a perspectiva vista de cima. No entanto, ela ainda precisa descobrir que os objetos têm uma aparência diferente nessa vista, e de que forma isso pode ser desenhado no papel. Os elementos menores, como um automóvel, são fáceis de abstrair, uma vez que em uma simples brincadeira de criança, como subir em uma árvore, por exemplo, é possível ver a forma de um carro visto de cima. A geometria das ruas já permite inferir uma noção mais aproximada de um mapa.

Figura 3: Mapa mental - Luna, 11 anos.

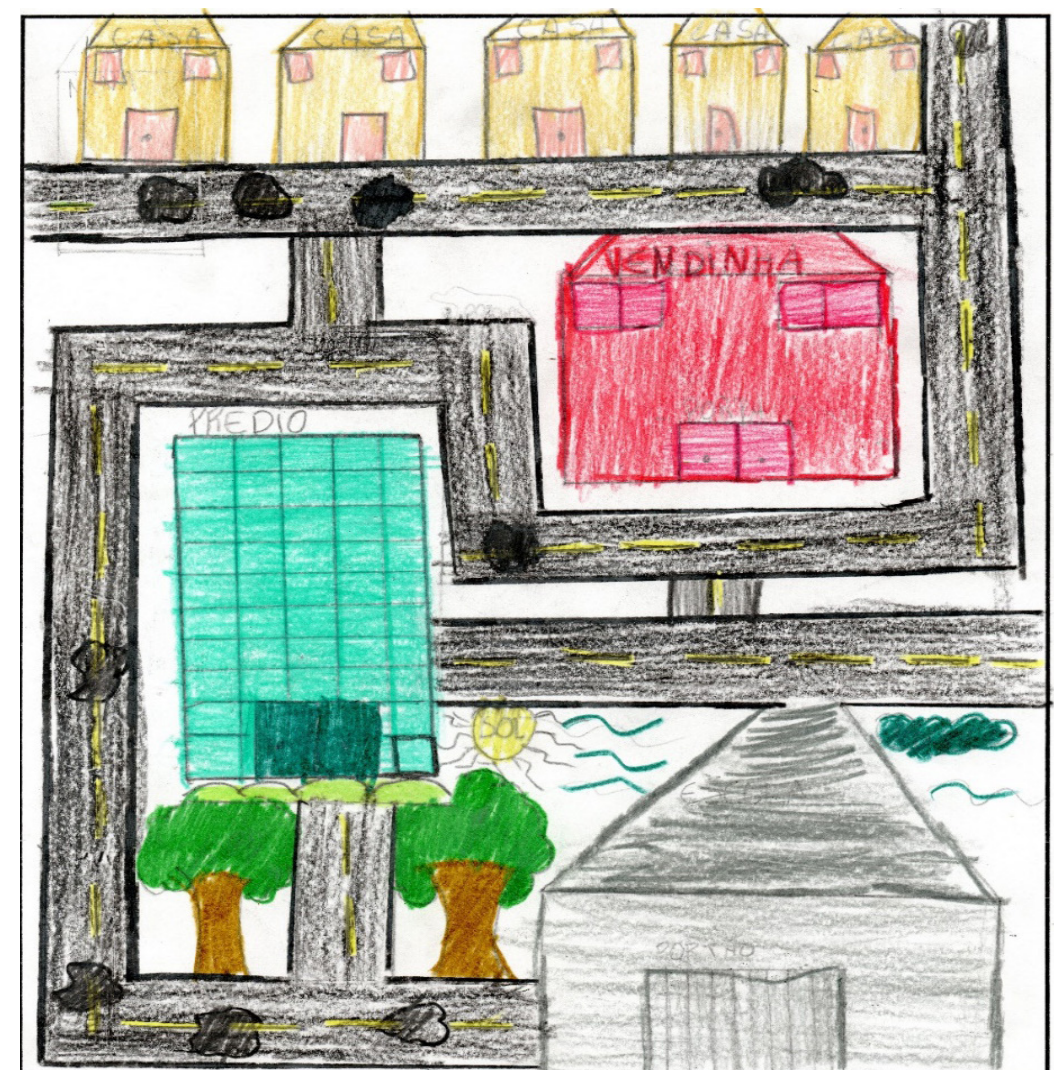

Novamente observamos a mistura de perspectivas, mas nesta representação cabe dar atenção à proporção dos elementos representados. As reduções proporcionais fazem parte do desenvolvimento de relações espaciais mais avançadas, com as euclidianas. Recorramos novamente a Almeida e Passini (2015, p. 39), que nos esclarecem que "a construção das relações euclidianas implica a conservação de distância, comprimento e superfície e a construção da medida de comprimento". Para tanto, é necessária a passagem do qualitativo (perto, longe) para o quantitativo, que pressupõe a medida expressa numericamente.

Na representação que segue (Fig. 4), a aluna optou por representar não um caminho contínuo, mas partes do seu trajeto, e em seguida os descreve em uma legenda. Elementos da paisagem construída prevalecem na representação, com a presença de poucos elementos da paisagem natural.

A representação da visão lateral, ou seja, as posições obedecem a maneira como se vê a imagem real quando se está posicionado em solo. A maioria dos mapas mentais apresentaram o modo de representação em forma horizontal, com edificações rebatidas. 
Quando encontradas representações verticais nos mapas mentais, elas se misturam com elementos na horizontal, ou seja, o estudante, ao buscar dar um formato mais parecido com o que vê quando está na posição de pé, traz essa mesma visualização ao realizar o mapa mental.

Figura 4. Mapa mental - Marrie, 11 anos

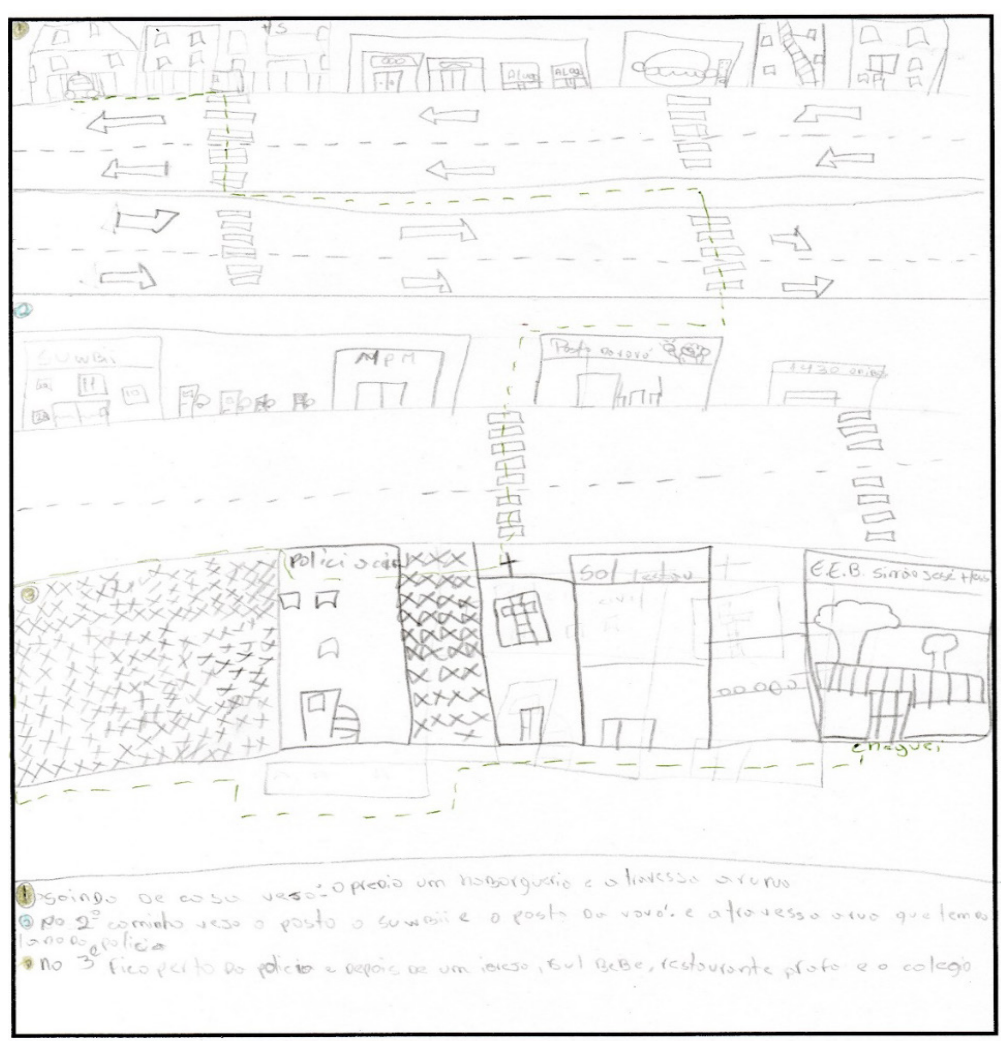

Apesar da densidade e dos detalhes apresentados na representação, a estudante optou em representar apenas partes deste caminho, o que pode ser um demonstrativo de dificuldades sobre a noção espacial do todo ou o desconhecimento do seu trajeto até a escola. Observa-se ainda que o realismo visual já está superado, onde a criança representa de uma forma mais parecida com o que está vendo, no entanto, o egocentrismo infantil ainda está presente de forma marcante.

No mapa mental a seguir (Fig. 5), a criança atrela sua representação apenas a elementos da paisagem construída (casas, prédios e o caminho), não havendo a presença de elementos móveis e humanos. As construções, algumas identificadas com letras, são grandes e desproporcionais umas às outras, e estão representadas do ponto de vista horizontal, diferente do caminho que foi representado a partir da visão vertical.

Seguindo a tendência das representações anteriores, há dificuldade em coordenar os pontos de vista, o que, para Passini (2012), é uma característica da fase egocêntrica entre as crianças, apresentada como uma incapacidade em analisar um ponto ou alguma coisa sem projeta-la a partir de seu próprio corpo. No caso dos adultos, não se refere a uma incapacidade cognitiva, mas possivelmente à falta de conhecimento e aplicação da 
técnica da vista aérea, ou por ainda não terem experienciado esse tipo de situação, como por exemplo, um voo ou uma filmagem aérea transmitida por mídias televisivas.

Figura 5. Mapa mental - Rafael, 11 anos.

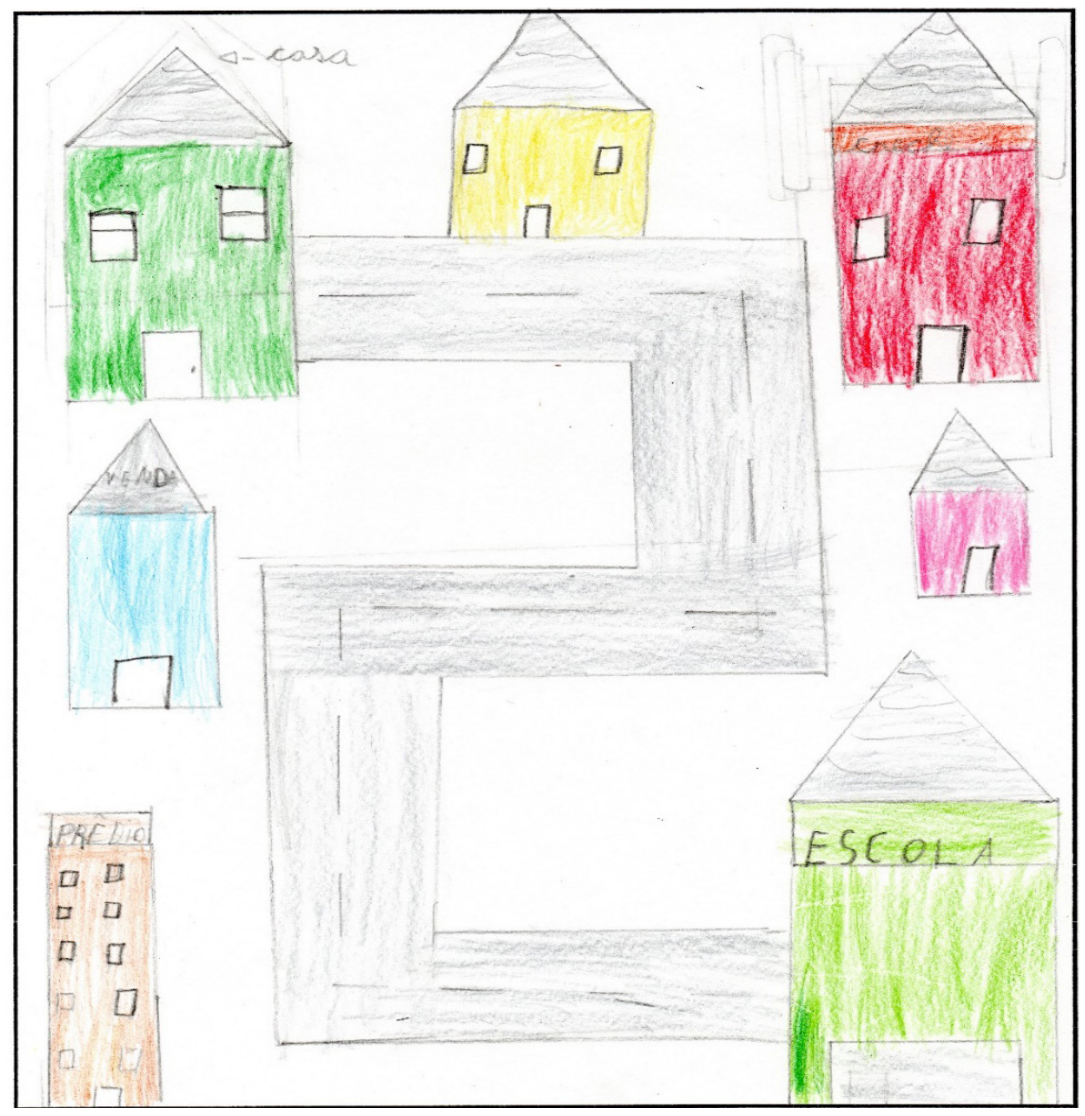

No próximo mapa mental (Fig. 6), com predomínio dos elementos da paisagem construída, alguns elementos móveis e da paisagem natural também são observados, como o automóvel e a árvore.

Neste mapa é possível notar que a estudante Nic teve a percepção da densidade de ocupação do solo, porém, a imaturidade espacial aparece na hora de expor no papel o seu desenho. As construções não têm uma linha de base, ou seja, a estudante ainda não superou o realismo visual, não consegue dar conta de pôr no papel, de forma organizada, o seu mapa mental. Esta ideia se reafirma quando analisamos a proporção entre os elementos desenhados, sendo que seu trajeto não foi concluído, uma vez que sua casa não está identificada.

É possível observar também certa desordem no direcionamento das ruas, confusão do ponto de vista e desproporcionalidade dos elementos especializados. Isso se deve ao fato de a nossa percepção espacial não ser decorrente da distância física entre os lugares, mas da afetiva (Tuan, 1983). 
Figura 6. Mapa mental - Nic, 10 anos.

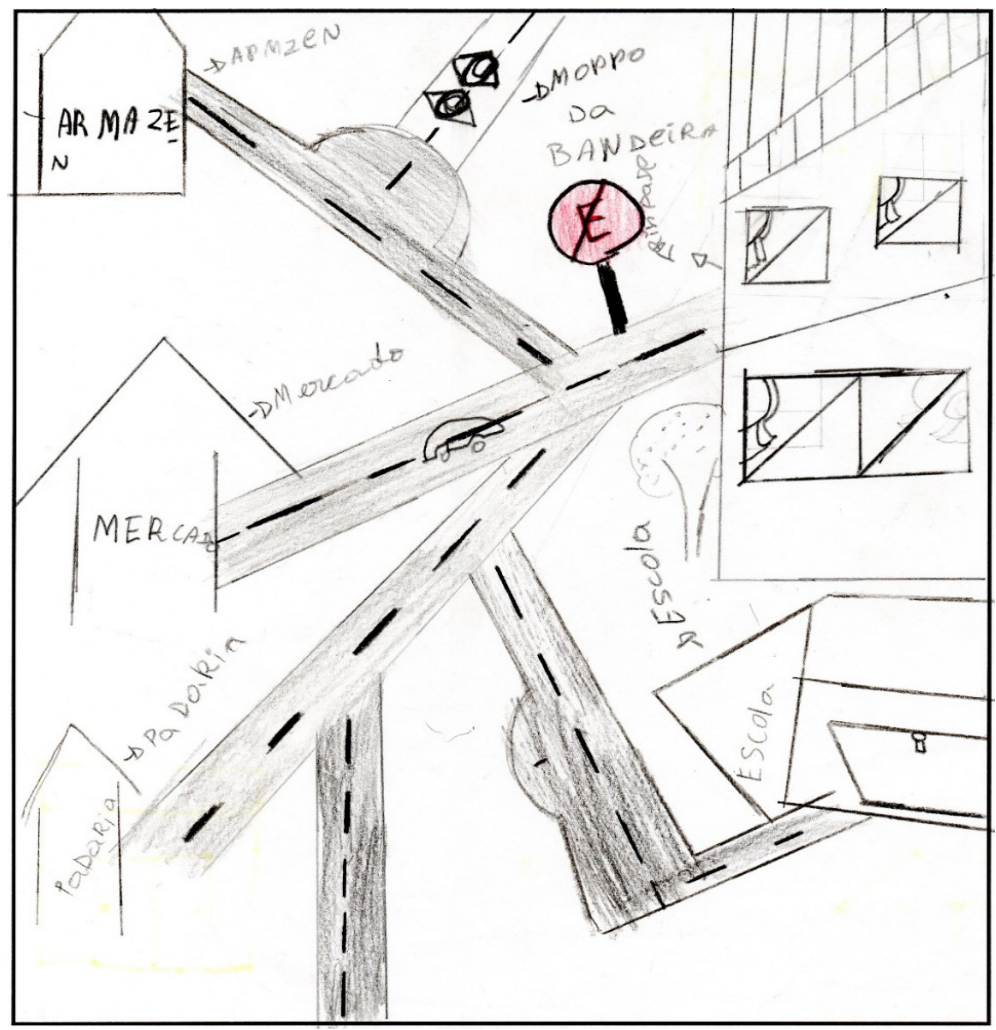

A noção de proporção precede e remete diretamente à noção de escala. A presença da noção de proporção é facilmente perceptível em mapas prontos e é essencial para o trabalho pedagógico, pois possibilita ao estudante compreender a generalização cartográfica, a relação entre a escala e a quantidade de elementos do mapa. A compreensão da função da escala é importante para que os estudantes percebam como se dá a transposição dos espaços reais para o que é desenhado nos mapas.

O último mapa mental analisado (Fig. 7), apresenta elementos da paisagem construída. Os mesmos foram rebatidos tomando por base o caminho, indicando noção de lateralidade, mas observa-se também a mistura de mais de um ponto de vista, com o caminho desenhado a partir de uma visão vertical e os demais elementos na horizontal. Não há uma continuidade dos imóveis, apresentando vários espaços vazios, mesmo sendo uma área densa em construções. É nítida a desproporcionalidade entre os elementos construídos, prédios, casas e ruas. Da mesma forma se apresentam os elementos naturais demasiadamente pequenos em comparação aos outros elementos e com a realidade. 
Figura 7: Mapa mental - Bianca, 11 anos.

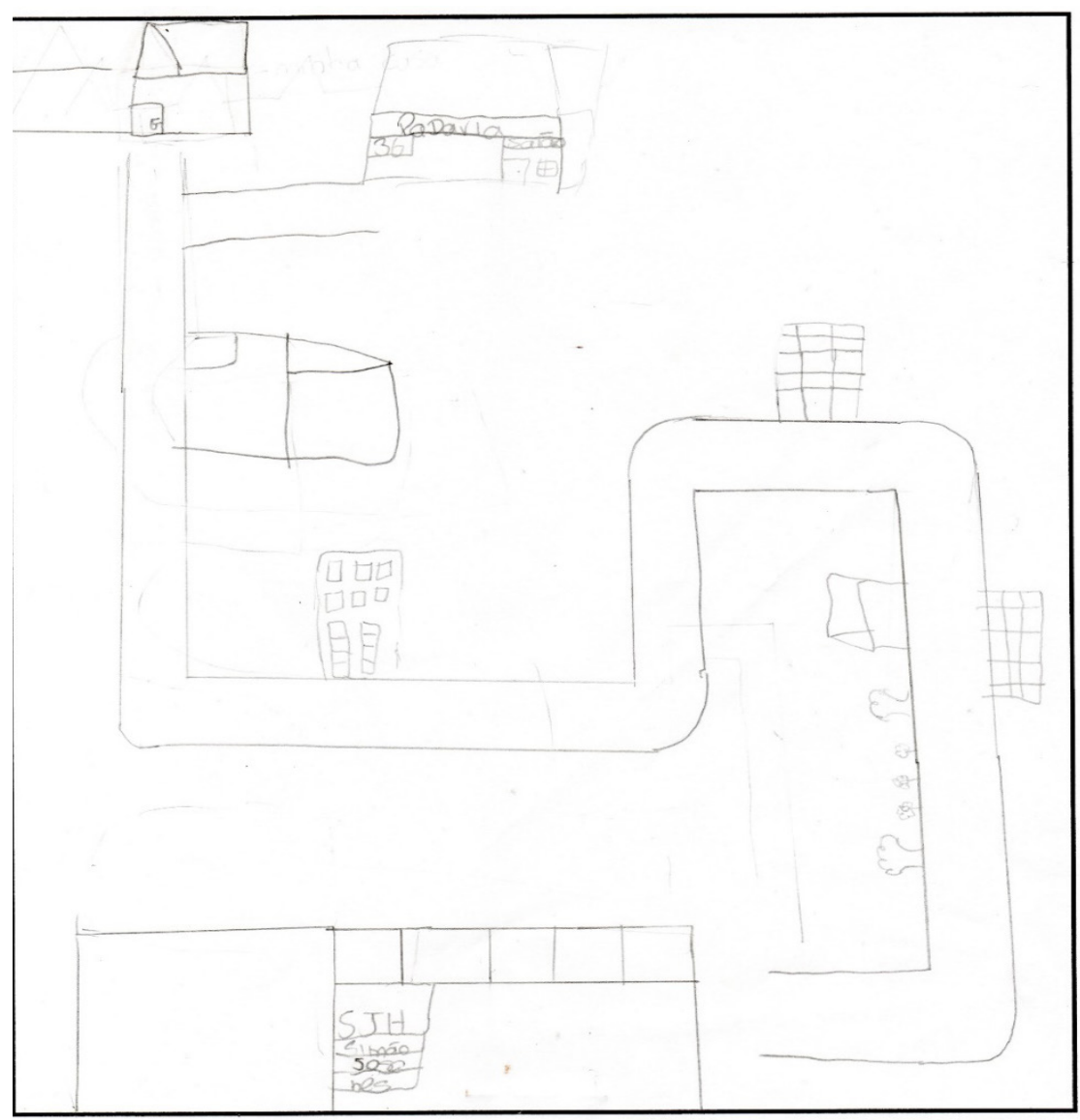

A estudante atribui importância à rua e às direções, mesmo não identificando quais as direções. Pode-se observar, também, a lateralidade espelhada, justificada como efeito do egocentrismo infantil, que só será superada quando a criança criar uma independência da posição do próprio corpo como referência espacial. No caso específico da representação, a face rebatida para o plano será voltada para cima, o que ocorre com a visão vertical. Como trata-se de objetos maiores, essa relação torna-se mais difícil, pois a criança não pode manipular os objetos a fim de ter a visão de todas as faces, como ocorreria com um cubo, por exemplo. Para construir essa consciência da orientação espacial é preciso, portanto, que a criança descentralize ou desvincule gradualmente a percepção espacial do seu próprio corpo.

A organização dos itens no espaço é um exercício importante em qualquer mapeamento. Nos mapas mentais não foram encontrados elementos organizados espacialmente de maneira proporcional ao terreno, e sim noções mais simples de lateralidade como direita e esquerda. Segundo Tuan (1983), os adultos e, principalmente, as crianças, vivem no chão e notam os objetos lateralmente, não sendo comum perceberem a paisagem por outro ângulo de vista. Na maioria das vezes, a experiência de olhar a paisagem a partir de outra perspectiva está relacionada apenas a viagens de avião ou à oportunidade de escalar uma montanha, ou ainda uma transmissão aérea pela televisão. 
Este argumento pode estar relacionado ao fenômeno de rebatimento, quando por exemplo, a representação de uma rua feita através de duas linhas verticais e paralelas com elementos construtivos (rebatidos) em ambos os lados das linhas. A maioria dos mapas mentais ainda manteve a linha de base horizontal, que remete a um único ponto de vista, o lateral, e apenas três deles apresentaram o rebatimento. Se por um lado, este fenômeno representa imaturidade e a não superação da fase do esquematismo, conforme Piaget (1978), por outro lado, pode indicar a primeira tentativa de trabalhar o plano em três dimensões, ou seja, a criança já concebeu a noção, mas não consegue transferi-la para o papel.

Em estudos específicos da área (Almeida, 2014), a criança a partir dos 6-7 anos consegue perceber a invariância da diferença entre as medidas nas figuras proporcionas, mas somente a partir de 8-9 anos ela é capaz de definir uma proporção matemática, caso ela tenha sido estimulada desde os anos iniciais.

A faixa etária expressa não é limitadora, sendo que o desenvolvimento cognitivo pode diferir de uma criança para outra, ou seja, é possível ter crianças de 8-9 anos que já tenham a noção de proporção bem consolidada. Por outro lado, é possível haver crianças com essa mesma faixa etária (ou com idade superior) que ainda necessitem de atividade que desenvolvam esse tipo de noção espacial.

Em algumas das representações observadas, é possível notar um alto grau de fragmentação dos elementos do espaço. As construções não foram representadas com uma continuidade, apresentam confusão na posição dos elementos, verificando-se, assim, que os discentes apresentam defasagem em relação às relações espaciais topológicas elementares.

\section{CONSIDERAÇÕES FINAIS}

A análise realizada possibilitou analisar o nível de desenvolvimento das relações espaciais dos estudantes do quinto ano do ensino fundamental, avaliando como estes utilizam as noções cartográficos na prática. Ao construir seu mapa metal, o estudante mobiliza os conhecimentos adquiridos, permitindo ao professor avaliar, no processo de construção dos mapas, o domínio das noções cartográficas e o nível de percepção da configuração e abstração dos espaços de vivência.

A partir da análise da interpretação quanto à forma de representação dos elementos da imagem, da interpretação quanto à distribuição dos elementos na imagem, da interpretação quanto à especificação dos ícones, entre outros aspectos ou particularidades, conclui-se que há um predomínio das formas de representação gráfica através de ícones e palavras complementando as representações gráficas. A representação denominada de 'mapa' na metodologia, não foi encontrada em nenhuma representação.

A maioria dos mapas mentais apresentou o modo de representação do ponto de vista horizontal. Quando encontradas representações do ponto de vista vertical, elas se misturam com elementos rebatidos na horizontal. Nitidamente buscam, com isso, dar um formato mais parecido à realidade, com o observador posicionado em frente ao objeto. Incapaz de ver de outra perspectiva, o estudante traz essa mesma visualização ao seu mapa mental. 
Quanto à especificação dos itens representados, há um predomínio significativo da paisagem construída, o que pode ser explicado pelo fato de as escolas se encontram em áreas densamente urbanizadas. No entanto, poucos representaram elementos humanos. Os elementos da paisagem natural aparecem com menor frequência, seguidos dos elementos móveis (como carros). Consideramos que a percepção dos estudantes com relação a especificação dos itens ainda é limitada, como se houvesse a ausência destes em seus trajetos, ou será que já constataram que não há a presença destes elementos (humanos, animais) nos mapas formais?

A grande maioria dos mapas apresenta problemas em relação à proporção, caracterizando-se pela desproporcionalidade de tamanho dos elementos em comparação com a realidade. No entanto, estas dificuldades podem estar relacionadas ao desenvolvimento cognitivo da faixa etária dos 10 a 11 anos, idade esta em que, segundo a literatura, ainda podem estar em desenvolvimento algumas noções.

Contudo, ao examinar as representações elaboradas por estudantes de faixas etárias mais avançadas, observou-se que não houve um desenvolvimento significativo da noção de proporção. Este fato permite-nos concluir que a faixa etária por si só não é um fator determinante para o desenvolvimento desta noção.

Com base nestes argumentos, ficou claro que a aquisição de habilidades de desenhos do espaço é longa e envolve a construção da perspectiva, da distância e da proporção (relações espaciais, projetivas e euclidianas). E somente a partir dessas aquisições, se pode pensar a aprendizagem de conceitos cartográficos (Almeida, 2014).

Concluímos, portanto, que os estudantes participantes da pesquisa não estão preparados para trabalhar com conteúdo cartográficos específicos. O estudo aponta ainda a necessidade de desenvolver atividades direcionadas no sentido de aprimorar as noções topológicas, projetivas e euclidianas, necessárias para a passagem do entendimento de representações gráficas para as cartográficas.

\section{REFERÊNCIAS}

Almeida, R.D. (2014). Do desenho ao mapa: iniciação cartográfica na escola. São Paulo: Contexto.

Almeida, R., \& Passini, E.Y. (2015). O espaço geográfico: ensino e representação. São Paulo: Contexto.

Braga, M.C. (2006). Aprender e ensinar Geografia: a visão de egressos de pedagogia da UEFS. (Tese de Doutorado em Educação). Universidade Federal de São Carlos, UFSCar, São Carlos, SP. Recuperado de https:// repositorio.ufscar.br/bitstream/handle/ufscar/2180/TeseMCBB.pdf?sequence=1\&isAllowed=y

Callai, H.C. (2003). O ensino de geografia: recortes espaciais para análise. In A.C. Castrogiovanni, H.C. Callai, N.O. Schaffer, \& N.A.Kaercher. A Geografia em sala de aula, práticas e reflexões. Rio Grande do Sul: Ed. UFRGS.

Callai H.C. (2005). Aprendendo a ler o mundo: a geografia nos anos iniciais do ensino fundamental. Cad. Cedes, 25(66):227-247.

Callai H.C. (2014). Estudar o lugar para compreender o mundo. In A.C. Castrogiovanni. Ensino de Geografia: prática e textualizações no cotidiano. Porto Alegre: Mediação.

Castrogiovanni, A.C. (2014). Ensino de geografia: práticas e textualizações no cotidiano. Porto Alegre: Mediação. 
Cavalcanti, L. (2004). Geografia, Escola e Construção do Conhecimento. Campinas: Papirus.

Francischett, M. (2007). A Cartografia Escolar Crítica. Recuperado de http://www.bocc.ubi.pt/pag/ francischett-mafalda-cartografia-escolar-critica.pdf

Harley, J.B. (2009). Mapas, saber e poder. Confins - Revista Franco-brasileira de Geografia, (5). Recuperado de https://journals.openedition.org/confins/5724?lang=pt

Joly, F. (1990). A Cartografia. Campinas: Papirus.

Katuta, Â.M. (2015). A linguagem cartográfica no ensino superior e básico. In N.N. Pontuschka, \& A.U. de Oliveira (Eds.) Geografia em perspectiva: ensino e pesquisa. (3a.ed., pp. 133-139).São Paulo: Contexto.

Kozel, T.S. (2001). Das imagens às linguagens do geográfico: Curitiba a Capital ecológica. (Tese de Doutorado). Universidade de São Paulo, USP, São Paulo, SP, Brasil.

Kozel, T.S. (2007). Mapas mentais: uma forma de linguagem: Perspectivas metodológicas. In Kozel, T.S. et al. (Ed.): Da percepção e cognição à representação. (pp. 114-138). São Paulo: Terceira Margem.

Kozel, T.S. (2013). Comunicando e representando: mapas como construções socioculturais. Geograficidade, 3:58-70. Recuperado de https:/ / periodicos.uff.br/geograficidade/article/view/12874/pdf.

Kozel, T.S. (2010). Representação do espaço, sob a ótica dos conceitos: mundo vivido e o dialogismo. Encontro Nacional dos Geógrafos, Porto Alegre, RS, Brasil, 16. (p.11).

Kozel, T.S., \& Galvão, Wilson. (2008). Representação e ensino de Geografia: contribuições teóricometodológicas. Ateliê Geográfico, 2(5):33-48. DOI: https:/ / doi.org/10.5216/ag.v2i3.5333

Ludwig, A.B. (2017). O ensino de Geografia nos anos iniciais do ensino fundamental: uma experiência no quinto ano. (Dissertação de Mestrado). Universidade Federal de Santa Catarina, UFSC, Florianópolis, SC, Brasil.

Nascimento, E., \& Ludwig, A.B. (2015). A educação cartográfica no ensino-aprendizagem de Geografia: reflexões e experiências. Revista Geografia Ensino e Pesquisa, 3:29-42. Recuperado de https://periodicos. ufsm.br/geografia/article/view/15535/pdf

Oliveira, C. (1993). Dicionário Cartográfico. 4a ed. Rio de Janeiro: IBGE.

Oliveira, L. (2010). Estudo metodológico e cognitivo do mapa. In Almeida, R.D. (Ed.) Cartografia Escolar. (pp. 15-41). São Paulo: Contexto,

Passini, E.Y. (2012). A alfabetização cartográfica e a aprendizagem de Geografia. São Paulo: Cortez.

Piaget, J. (1978). A formação do símbolo na criança. Rio de janeiro: Zahar.

Pontuschka, N.N., Paganelli, T.I., \& Cacete, N.H. (2009). Para ensinar e aprender Geografia. São Paulo: Cortez.

Richter, D. (2011). O mapa mental no ensino de Geografia: concepções e propostas para o trabalho docente. São Paulo: Cultura Acadêmica.

Richter, D., Marin, F.A.D.G., \& Decanini, M.M.S. (2010). Ensino de Geografia, espaço e linguagem cartográfica. Mercator, 9(20):163-178.

Rosa, O. (2008). Geografia e pedagogia: o professor dos anos iniciais do ensino fundamental em Catalão (GO). (Tese de Doutorado em Geografia). Universidade Federal de Uberlândia, UFU, Uberlândia, GO, Brasil. Recuperado de https:/ / repositorio.ufu.br/bitstream/123456789/15907/1/Odelfa.pdf

Seemann, J. (2003). Mapas, mapeamentos e a Cartografia da Realidade. Geografares, 4:49-60.

Simielli, M.E. (2013). Cartografia no ensino fundamental e médio. In Carlos, A. F. (Ed.). A Geografia em sala de aula. (pp. 50-61). São Paulo: Contexto.

Souza, J.G., \& Katuta, Â.M. (2001). Geografia e conhecimentos cartográficos: a cartografia no movimento de renovação da geografia brasileira e a importância do uso de mapas. São Paulo: Ed. UNESP.

Tuan, Y.F. (1980). Topofilia: um estudo da percepção, atitudes e valores do meio ambiente. São Paulo: DIFEL.

Tuan, Y.F. (1983). Espaço e Lugar: a Perspectiva da Experiência. São Paulo: DIFEL. 
Zuba, J.A.G. (2006). Ensino de geografia e formação de professores das séries iniciais do ensino fundamental: das expectativas do curso normal superior da Unimontes à realidade. (Dissertação de Mestrado em Geografia). Universidade Federal de Uberlândia, UFU, Uberlândia, MG, Brasil. Recuperado de https://repositorio. ufu.br/bitstream/123456789/16196/1/JAGZubaDISSPRT.pdf

Data de submissão: 15/jul./2020

Data de aceite: 28 /ago./2020 